\title{
Review - Lichen-Associated Bacteria as a Hot Spot of Chemodiversity: Focus on Uncialamycin, a Promising Compound for Future Medicinal Applications
}

Authors

Affiliations
Delphine Parrot $^{1 *}$, Nathalie Legrave ${ }^{1 *}$, David Delmail ${ }^{1}$, Martin Grube $^{3}$, Marcelino Suzuki $^{2}$, Sophie Tomasi ${ }^{1}$

${ }^{1}$ UMR CNRS 6226, Institut des Sciences Chimiques de Rennes, Equipe PNSCM “Produits naturels - Synthèses - Chimie Médicinale", UFR Sciences Pharmaceutiques et Biologiques, Univ. Rennes 1, Université Européenne de Bretagne, Rennes, France

2 Sorbonne Universités, UPMC Univ. Paris 06, CNRS, Laboratoire de Biodiversité et Biotechnologies Microbiennes (LBBM), Observatoire Océanologique, F-66650 Banyuls/Mer, France

${ }^{3}$ Institut für Pflanzenwissenschaften, Karl-Franzens-Universität, Graz, Austria

\section{Key words}

- lichens

bacterial communities

- chemodiversity

- drug discovery

- bioactive compounds

- uncialamycin received January 25, 2016 revised March 16, 2016 accepted March 21, 2016

\section{Bibliography}

DOI http://dx.doi.org/

10.1055/s-0042-105571

Published online May 24, 2016

Planta Med 2016; 82:

1143-1152 @ Georg Thieme

Verlag KG Stuttgart · New York . ISSN 0032-0943

\author{
Correspondence \\ Sophie Tomasi \\ UMR CNRS 6226 \\ Institut des Sciences Chimiques \\ de Rennes \\ Equipe PNSCM “Produits \\ naturels - Synthèses - Chimie \\ Médicinale" \\ UFR Sciences Pharmaceutiques \\ et Biologiques \\ Univ. Rennes 1 \\ Université Européenne de \\ Bretagne \\ 2 Avenue du Pr. Léon Bernard \\ F-35043 Rennes \\ France \\ Phone: + 330223234817 \\ Fax: + 330223234704 \\ sophie.tomasi@univ-rennes1.fr
}

\section{Abstract}

$\nabla$

This review presents the state of knowledge on the medicinal potential of bacteria associated with lichens. In fact, besides the classical symbiotic partners (photobiont and mycobiont) forming the lichen thallus, associated bacteria have been recently described as a third partner. Various studies demonstrated the diversity of these communities with a predominance of Alphaproteobacteria. Bacterial groups more relevant for sec-

\section{Introduction}

$\nabla$

Despite significant treatment advances, diseases such as cancer and microbial infections remain major public health issues due to the emergence of antibiotic resistance and the weak efficiency of current anticancer therapies. Therefore, biotechnological advances and the search of more specific and effective drugs are important challenges for pharmaceutical companies worldwide. The recent discovery of teixobactin from uncultivated soil bacteria highlights the unexplored microbial sources as treasure chests for the access to new interesting bioactive drugs [1]. Among underexplored sources, lichens are unique and are classically described as a symbiotic association between a photobiont (green alga and/or cyanobacterium) and a mycobiont. Most lichens are outstanding in their capacities to produce specific secondary metabolites that present biological activities, e.g., antioxidant, cytotoxic, and antimicrobial activities [2-8]. These organisms were also known to represent habitats for diverse lichenicolous fungi, with a high biosynthetic potential $[9,10]$. Recent molecular approaches have also demonstrated the high diversity of lichen-

\footnotetext{
${ }^{*}$ These authors contributed equally to this paper.
}

ondary metabolite synthesis have also been revealed. This article summarizes studies reporting the abilities of these communities to produce metabolites with relevant bioactivities. The biotechnological interest of these bacteria for drug discovery is highlighted regarding the production of compounds with therapeutic potential. Special focus is given to the synthesis of the most promising compound, uncialamycin, a potent enediyne isolated from a Streptomyces sp. associated with Cladonia uncialis.

associated bacterial communities that comprise millions of bacterial cells per gram of lichen thallus [11-21]. These associated organisms form stable and specific communities and thus represent as a whole a third partner of the lichens symbiosis [22]. They particularly colonize hydrophilic surfaces of lichens and are also incorporated within the extracellular fungal matrix [13]. These bacteria could either live as biofilm-like structures or as individual colonies [23]. These communities were characterized by culture-independent methods (e.g., pyrosequencing and FISH/CLSM) [12-15, 17, 18,20,21,24-26] and culture-dependent approaches [11,13,27-36]. While proteobacteria usually dominate the bacterial community, members of other groups are present as well, in particular Actinobacteria, Bacteroidetes, Acidobacteria. In a recent review, we focused on the diversity of these communities, particularly in the point of view of the presence of biotechnologically interesting bacteria [37].

These species-specific diversity patterns of bacteria associated with lichens are influenced by various parameters such as extrinsic factors (e.g., exposure, substrate type, and location) and intrinsic factors (e.g., lichen species, age and part of the lichen thallus, and chemical composition of the lichen) [16-18,23,26,38-40] (O Fig. 1). Indeed some studies highlighted the prevalence of 


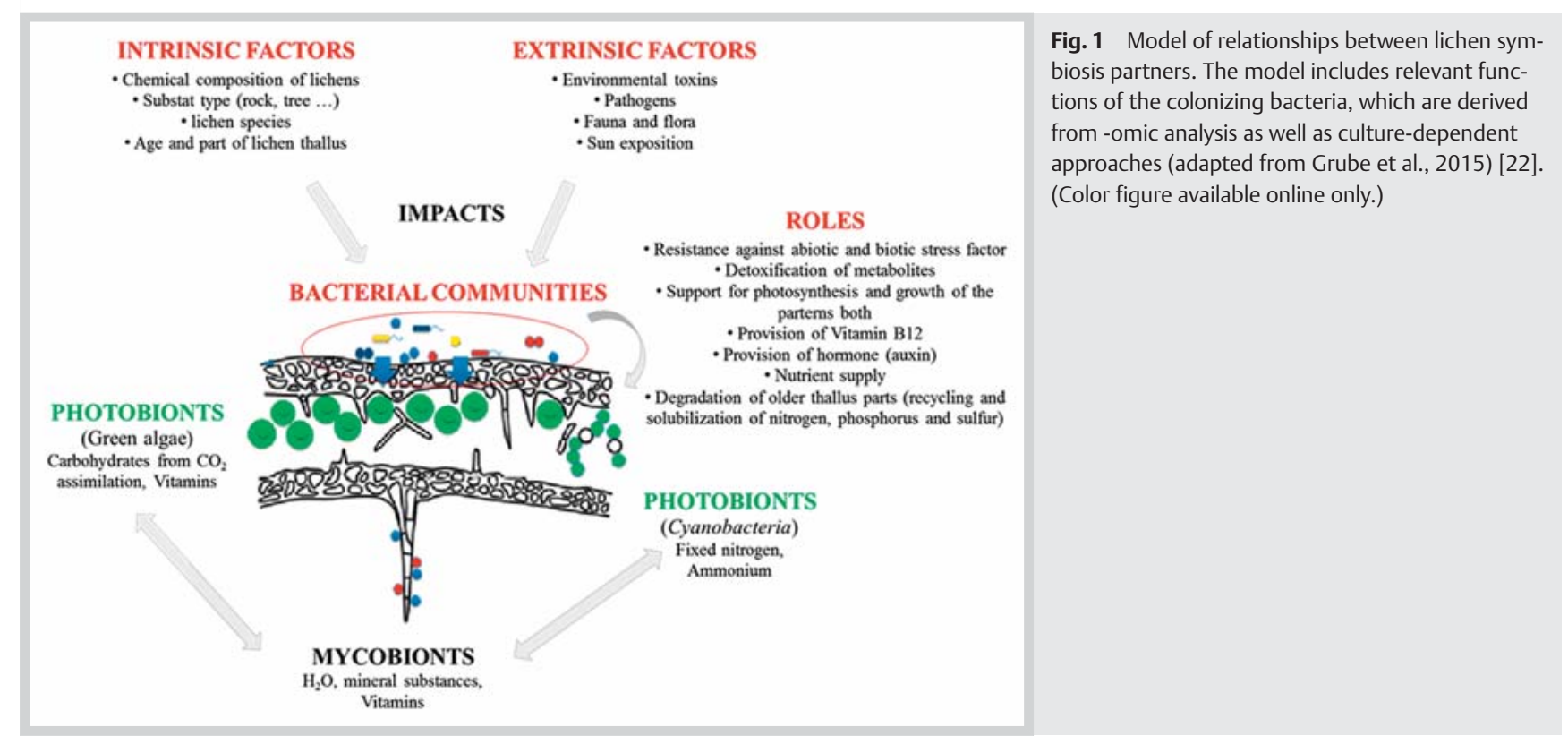

Acetobacteraceae (Alphaproteobacteria) associated with lichens, which is a proteobacterial family known to harbor nitrogen-fixing bacteria $[13,17,18,20,25,39]$. Their presence may also be correlated to their ability to use carbon sources furnished by lichen mycobionts such as mannitol [20]. Moreover, it was reported prevalent secondary bioactive metabolites from lichens such as usnic acid, a abundant in some lichen species and with multiple biological activities (such as antibacterial, cytotoxic, and antifungal) [3-6], only influenced the bacterial diversity but not its abundance. Accordingly, bacterial communities associated with lichens producing usnic acid were more specific and more resistant to this metabolite $[23,26]$. All of these results suggest a closer relationship between the different partners.

The functional implications of associated bacteria in the lichen symbiosis remain to this day largely unexplained and unexplored. Nonetheless, some nonexclusive hypotheses have been proposed and/or reported. Globally, these hypotheses indicate that the symbiotic microbial communities in lichens might play an important role in (1) nutrient supply, especially nitrogen, phosphorus, and sulfur, (2) recycling nutrients, (3) resistance against biotic stress factors by the production of bioactive metabolites (e.g., uncialamycin, aminocoumarins, angucyclines, butenolides), (4) resistance against abiotic factors, (5) support of photosynthesis by the provision of vitamin B12, (6) fungal and algal growth support by the provision of hormones, (7) detoxification of metabolites, and (8) degradation of older parts of the lichen thallus $[17,19,21-25,41,42]$ ( Fig. 1). Even if bacteria or their metabolites could be present in a low amount in the holobiont, they could possibly play interesting ecological or biological roles. Further approaches to determine their localization inside the lichen thallus, the level of the activity of the produced metabolites, and the ability of the latter ones to dissipate into the thallus must be explored. A better understanding of the roles of small chemical compounds (called by Davies the "parvome" [43]) in cell-tocell communication, particularly those produced by microbial organisms, will permit the development of rational approaches for the discovery of new drugs. In this context, lichen-associated bacteria could be interesting sources of bioactive natural molecules.
We will describe herein the isolation and the chemical characterization associated with the biological properties of compounds isolated from the cultivable bacteria [27-32,34,44]. We will focus more precisely on uncialamycin, a compound isolated from a Streptomyces strain. Due to its potent DNA damage activity, this molecule with a reactive enediyne unit constitutes a valuable lead for pharmaceutical industries. As a result, intensive efforts have been implemented for the synthesis of this complex structure.

\section{Biosynthetic Potential of Lichen-Associated Bacteria $\nabla$}

The study of culturable lichen-associated bacterial communities led to the discovery of new bacterial species [27-32,34,36,45, 46]. Six new strains of Actinobacteria were thus isolated from unidentified lichens collected in Japan, e.g., Schumannella luteola sp. nov. [28], Leifsonia lichenia. sp. nov [27], Actinomycetospora iriomotensis sp. nov. [36], Nocardioides exalbidus sp. nov. [31], one from an unidentified lichen Actinoplanes sp. (MA7066 (ATCC 55532) from Spain [46], and one strain Frondihabitans cladoniiphilus sp. nov. from Cladonia arbuscula [45]. Two new Streptomyces strains were isolated from lichens belonging to the Cladonia genus (Cladonia gracilis: strain L-44 [29] and C. uncialis: Streptomyces uncialis $[30,34,44])$ and four other Streptomyces sp. from lichens collected in Japan (strains RI104-LiC106 and RI104LiB101) [32] or in Spain (Streptomyces cyaneofuscatus M-27 and S. carnosus M40) [47]. At least 14 novel culturable bacterial strains associated with lichens were thus identified and gave new opportunities to discover bioactive metabolites of interest. To date, the bacterial communities of only a few lichens have been studied as a source of original metabolites: Cladonia gracilis and Cladonia uncialis both collected in Canada and one unidentified lichen from Japan. Additionally, one recent study reports the presence of various interesting metabolites from S. cyaneofuscatus $\mathrm{M}-27$ and S. carnosus M-40 isolated from unidentified lichens (e.g., antifungal compound maltophilin, antitumor daunomycin, or cosmomycin from the first strain or antibiotic and anti-inflammatory lodophorine $\mathrm{B}$ from the second one), but with the caveat 
that these identifications were only by HPLC [47] and production must eventually be confirmed by further chemical characterization. Notably, all reports concerning the production of interesting chemicals by lichen-associated bacteria deal with Actinobacteria, likely due to their known biotechnological potential, and even though it has been shown that Alphaproteobacteria are the predominant bacterial group on most lichens. Actinobacteria isolated from natural sources are widely recognized for their production of secondary metabolites with unusual structures and potent biological activities [48]. Among them, many known antimicrobials of major interest have been reported (e.g., erythromycin, streptomycin, and tetracycline). Moreover, relatively few interesting compounds were reported from Proteobacteria (including Alphaproteobacteria) in comparison with Actinobacteria [49]. As lichens host a significant number of Actinobacteria $[35,37]$, efforts have been made to isolate and study such bacteria from lichens, especially Streptomyces, as a promising resource for new lead compounds in drug development $[37,48]$. This section provides the state of knowledge of the chemical potential of lichen-associated bacteria and demonstrates the real chemodiversity that these organisms could offer for medicinal applications. Secondary metabolites like angucyclin, the butenolide derivative JBIR-89, coumabiocins, uncialamycin, unciaphenol, and cladoniamides have been isolated from Streptomyces inhabiting lichens. Even though the ecological role of these compounds is still unclear, they have demonstrated remarkable biological activities (e.g., anticancer and antibacterial). Considering the complexity to identify them and their wide spectrum of biological activities, several research groups have achieved their total syntheses. Focus will be made on the total synthesis of uncialamycin and its analogues, as this molecule presents interesting cytotoxic activity associated with a specific mechanism of action.

\section{Isolation and Bioactivity of Metabolites Produced by Culturable Bacteria \\ $\nabla$}

During their investigations, Motohashi and coworkers focused their attention on the isolation and chemical characterization of Streptomyces strains from a lichen collected at Risiri Island, Hokkaido prefecture, Japan [32]. By searching the homology of their 16S rRNA gene sequence with other bacteria, they identified strains RI104-LiC106 and RI104-LiB101 as new species of the genus Streptomyces. Partition using ethyl acetate was performed on an acetone crude extract of the mycelium produced during the fermentation (180 r.p.m., $27^{\circ} \mathrm{C}, \mathrm{pH} 7.2,5 \mathrm{~d}$ ). Chemical studies of the dried residues using reverse-phase chromatography led to the discovery of a new 1,1-dichlorocyclopropane-containing angucycline (1) from the culture broth of RI104-LiC106, and a new butenolide, designated as JBIR-89 (2), from RI104-LiB101 (O Fig. 2). The isolation of angucycline 1 constituted the first report of a tetraphene containing a dichlorocyclopropane ring [32]. Bioactivity studies on angucycline $\mathbf{1}$ showed antibacterial activity against Micrococcus luteus (diameter of inhibition zone: $11 \mathrm{~mm}$, $\mathrm{c}=25 \mu \mathrm{g}$ on a $6-\mathrm{mm}$ disk) and a lack of activity against Candida albicans and Escherichia coli. While angucycline 1 exhibited weak cytotoxic activity against HeLa $\left(\mathrm{IC}_{50}=36 \mu \mathrm{M}\right)$ and ACC-MESO-1 $\left(\mathrm{IC}_{50}=52 \mu \mathrm{M}\right)$ cells, the butenolide derivative (2) was not cytotoxic against either of the two cell lines [32].

Another Streptomycetaceae strain, Streptomyces L-4-4, sharing 98\% identity with the strain Streptomyces caeruleus based on $16 \mathrm{~S}$ rRNA analysis, has been isolated from the surface of the li-

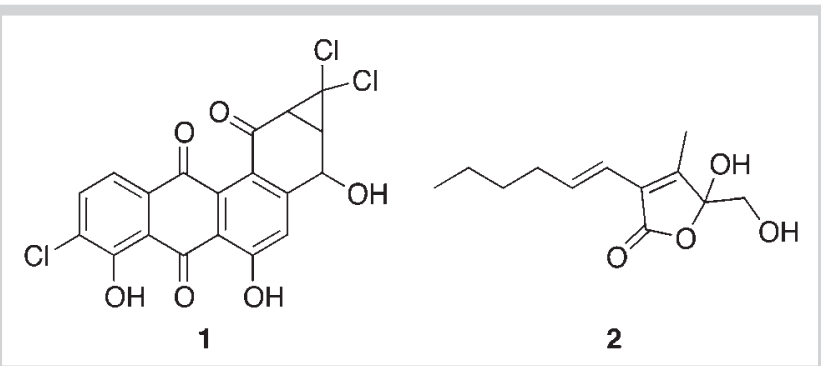

Fig. 2 Structures of angucycline $\mathbf{1}$ and the butenolide JBIR-89 (2).

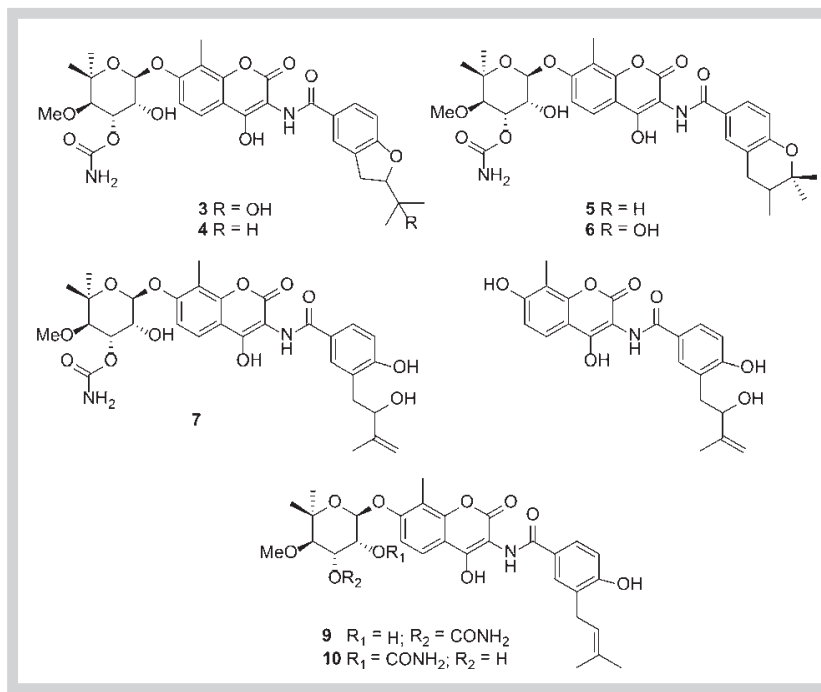

Fig. 3 Structures of coumabiocins A-F (3-8), novobiocin (9), and isonovobiocin (10).

chen Cladonia gracilis from Mount Fromme in British Columbia using ISP4 (International Streptomyces Project 4) media plates supplemented with $50 \mu \mathrm{g} / \mathrm{ml}$ of cycloheximide and $20 \mu \mathrm{g} / \mathrm{ml}$ of nalidixic acid [29]. Studies of the butanol-soluble extract of fermented Streptomyces L-4-4 (250 r.p.m., $30^{\circ} \mathrm{C}, \mathrm{pH} 7.0,7 \mathrm{~d}$ ) highlighted an activity in hyphae formation inhibition (HFI) assays of prokaryotic whole cells $[50,51]$. This analysis indicated the presence of protein kinase inhibitors in this extract. Further investigations of this extract led to the isolation of new aminocoumarins named coumabiocins A-F (3-8), along with two known compounds, novobiocin (9) and isonovobiocin (10). Coumabiocins A-E (3-7) contain three structural elements: a 3-amino-7hydroxycoumarin core linked at the 3-amino group via a prenylated 4-hydroxybenzoic acid moiety and at the 7-position to an $L$ noviosyl sugar. Only coumabiocin $F(8)$ lacks the sugar moiety (O Fig. 3).

The antimicrobial efficacy of novobiocin (9) had been confirmed in several clinical trials during the 1960s. After approval, it has been used as an antibiotic for the treatment of human infections $[52,53]$. However, novobiocin is no longer used due to its toxicity. Significant inhibitory activities against Streptomyces 85E have been observed for coumabiocins A-E (3-7) (10-15 mm clear zone of inhibition at $20 \mu \mathrm{g} / \mathrm{disk}$ ), while moderate activities were detected at lower concentrations ( $10 \mathrm{~mm}$ bald zone of inhibition at $2.5 \mu \mathrm{g} /$ disk). Coumabiocin $\mathrm{F}(\mathbf{8})$, where the $L$-noviosyl sugar 
group is absent, was inactive, suggesting that the $L$-noviose group is essential for the activity in this class of molecules.

Studies of the bacterial communities of the lichen Cladonia uncialis (Pitt River, British Columbia) by J. Andersen and coworkers revealed a Streptomyces isolate putatively belonging to a new species named "S. uncialis" [30]. Based on its 16S rRNA sequences, this strain is related (98.4\%) to Streptomyces rubrogriseus. Laboratory cultures on ISP4 solid agar medium $\left(30^{\circ} \mathrm{C}, 14-\right.$ $21 \mathrm{~d}$ ) followed by extractions with EtOAc and purification steps of the crude extract by flash $\mathrm{C}_{18}$ reverse-phase chromatography and reverse-phase HPLC yielded uncialamycin (11), a new enediyne antibiotic. The structure of uncialamycin (11), similar to that of dynemicin A (12) isolated from Micromonospora chersina [54], combines a 10-membered enediyne with an anthraquinone substructure (๑ Fig. 4).

Structural similarities between uncialamycin (11) and dynemicin A (12) strongly suggest that they share the same biosynthetic pathway. Uncialamycin (11) could result from a degradation of a dynemicin-like precursor in which the C-5, C-6, and C-30 skeletal carbon atoms have been truncated. This metabolite showed in vitro antibacterial activities against gram-positive and gram-negative human pathogens, including Burkholderia cepacia $(\mathrm{MIC}=$ $0.001 \mu \mathrm{g} / \mathrm{mL}$ ), a major cause of morbidity and mortality in patients with cystic fibrosis, methicillin-resistant Staphylococcus aureus $(\mathrm{MIC}=0.0000064 \mu \mathrm{g} / \mathrm{mL})$, and Escherichia coli $(\mathrm{MIC}=$ $0.002 \mu \mathrm{g} / \mathrm{mL}$ ) [30]. Later, the synthesis of this compound and isomers confirmed the activities against $B$. cepacia $(\mathrm{MIC}=0.0004 \mu \mathrm{g} /$ $\mathrm{mL}$ ), S. aureus (MIC $=0.0002 \mu \mathrm{g} / \mathrm{mL}$ ), and allowed for the detection of further bioactivities on Staphylococcus epidermidis (MIC = $0.00009 \mu \mathrm{g} / \mathrm{mL})$, Streptococcus pneumoniae $(\mathrm{MIC}=0.0004 \mu \mathrm{g} / \mathrm{mL})$, and Enterococcus faecalis (MIC $=0.002 \mu \mathrm{g} / \mathrm{mL}$ ) [55].

Enediyne compounds are remarkable active natural products, which own a unique and versatile core [56]. They are potent antitumor agents and have been studied extensively for use in the form of targeted antibody complexes [57-59]. To date, all natural enediynes exhibit cytotoxic effects as they act on duplex DNA and cause single- and double-stranded breaks. It is the result of the action of benzenoid diradicals formed by a Bergman rearrangement of the antibiotic molecule within the minor groove of the target DNA [60-62] ( $\bullet$ Fig. 5).

Initial studies indicate that uncialamycin reacts with plasmid DNA leading to its degradation, and it is thus not surprising it presents potent activities against a broad panel of cancer cells, including Taxol-resistant ovarian cells (1A9/PTX10; IC $\mathrm{IC}_{50}=6 \times$ $10^{-11} \mathrm{M}$ ) and epothilone B-resistant cells (1A9/A8; $\mathrm{IC}_{50}=9 \times$ $10^{-12} \mathrm{M}$ ) [55]. Interestingly, an additional chemical study on this Streptomyces strain recently described the isolation of unciaphenol (13) by a supplementary purification using an LH-20 Sephadex column [44]. This compound was described as putative naturally occurring even if it corresponds to a Bergman cyclization product analogue of uncialamycin ( Fig. 6). This compound was devoid of cytotoxicity, but exhibited an interesting in vitro antiHIV activity against various strains resistant to antiretroviral compounds with an $\mathrm{IC}_{50}$ range of 6.5 to $14.1 \mu \mathrm{M}$ [44].

Later, investigations of the EtOAc extracts of the culture of S. uncialis have resulted in the isolation of new alkaloids named cladoniamides A-G (14-20) (๑ Fig. 7). These metabolites are derived of rearrangement and degradation of indolocarbazole precursors. The indolocarbazole alkaloids are a family of natural products isolated from marine invertebrates and cultures of diverse microorganisms [63].

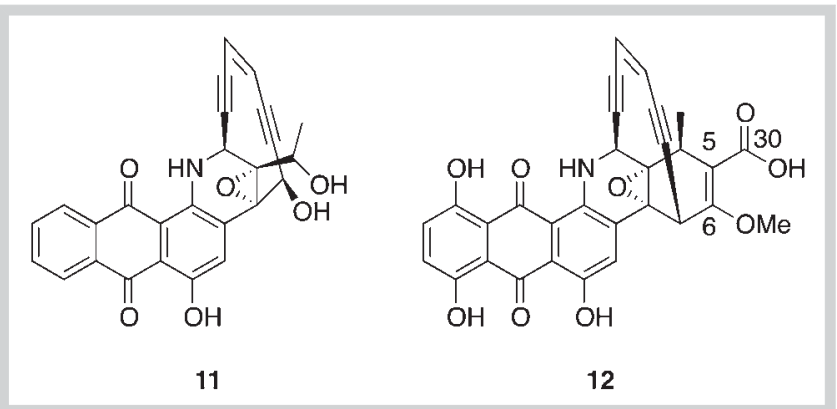

Fig. 4 Structures of uncialamycin (11) and dynemicin A (12).
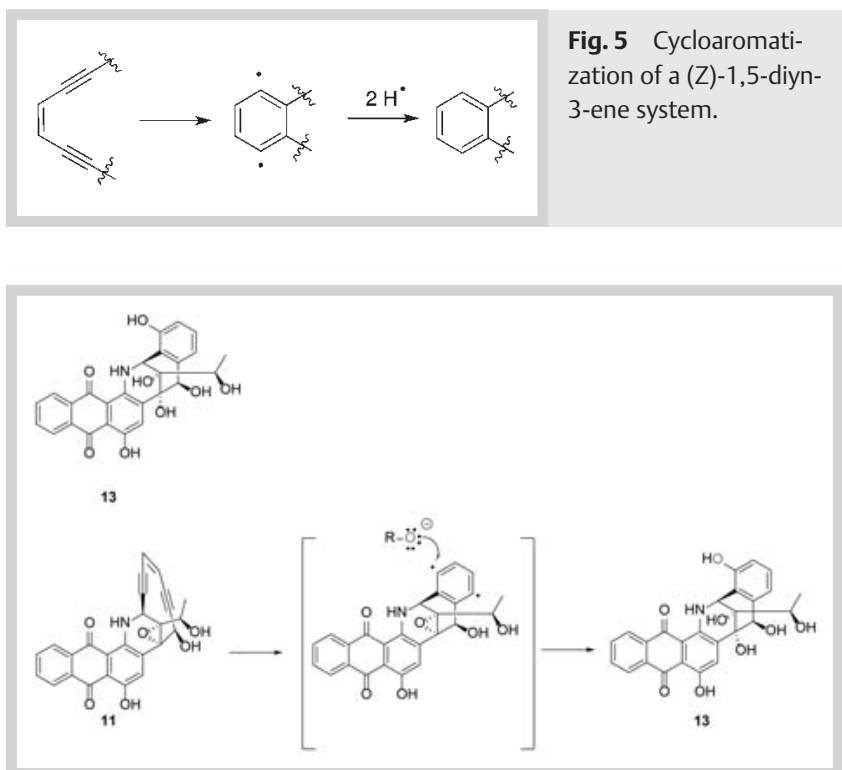

Fig. 6 Structures of unciaphenol and its putative obtention from uncialamycin (11).

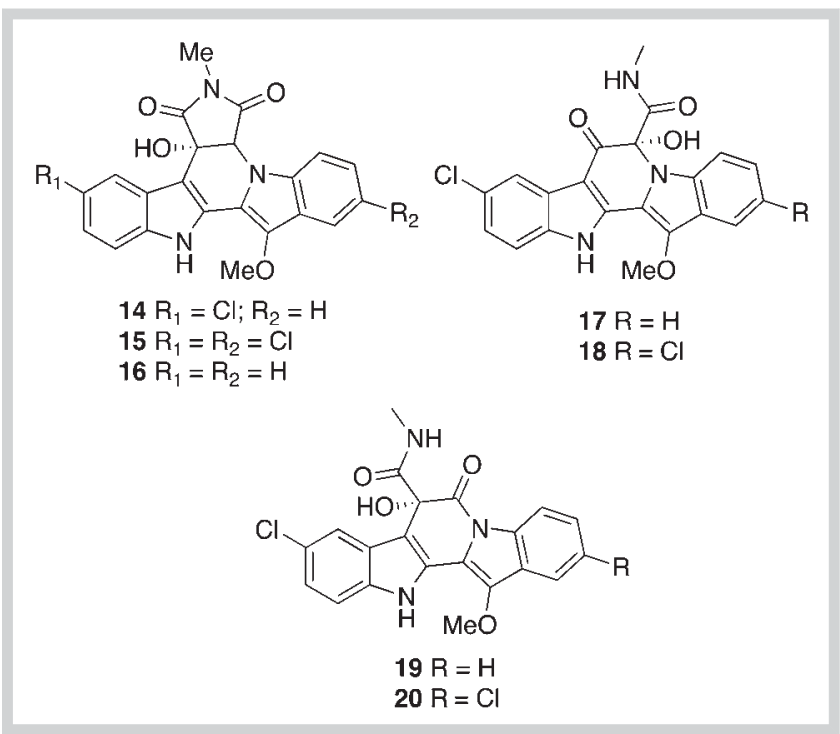

Fig. 7 Structures of cladoniamides A-G (14-20). 
During bioassays, only cladoniamide G (20) demonstrated cytotoxic activities on human breast cancer MCF-7 cells in vitro at $10 \mu \mathrm{g} / \mathrm{mL}$. Indolocarbazole alkaloid derivatives such as cladoniamides are new aglycons that could be used to obtain new staurosporine/rebeccamycin (21/22) analogues ( $\boldsymbol{0}$ Fig. 8) by chemical and biotechnological approaches. Staurosporine and rebeccamycin have shown a high potential for the development of anticancer drugs [64-69], as these two molecules are potent inhibitors of protein kinases and topoisomerase-1, respectively. Several analogues of staurosporine (21) and rebeccamycin (22) have entered clinical trials.

Besides the study of various Streptomyces, one patent from Singh and coauthors reports the production of actinoplanic acids $A$ and B (O Fig. 9) from Actinoplanes sp. isolated from a Spanish lichen [46]. These 20-membered macrocyclic polycarboxylic acids exhibited potent and selective inhibition of farnesyl protein transferase with $\mathrm{IC}_{50}$ of $230 \mathrm{nM}$ and $50 \mathrm{nM}$ respectively $[46,70,71]$, and thus inhibited the farnesylation of the oncogene protein Ras, one interesting target for anticancer therapies [72].

After the overview of the different metabolites isolated from lichen-associated bacteria, it appeared that these bacteria represent a very promising source of structurally diverse bioactive compounds. Reports of secondary metabolites from lichen-associated bacteria mention the use of various culture conditions of the target bacteria depending on their intrinsic characteristics. Parameters like temperature, $\mathrm{pH}$, and media (solid or liquid) considerably impact the production of these metabolites. However, these culture conditions are very far from the in situ environment of the bacterial strains on the lichen, which are confronted with other biotic and abiotic factors. As a consequence, the metabolomic potential of these microorganisms are still poorly understood and, thus, underexploited. Despite these difficulties, the isolated metabolites belong to important classes of molecules (e.g., aminocoumarins, indolocarbazoles, alkaloids, enediynes). Uncialamycin is one of these examples as it presents a broad spectrum of antibacterial activities and interesting cytotoxic properties associated with an original mechanism of action. This atypical structure jointly with these impressive bioactivities has therefore generated interest for chemical synthesis.

\section{Synthesis of Uncialamycin}

$\nabla$

Considering the small production yields of uncialamycin by S. uncialis and its high biological potential, different research groups have attempted the total synthesis of this metabolite. In the remainder of this section we will discuss two major synthetic strategies.

The first strategy, developed by Nicolaou and coworkers, is based on the use of the building blocks 25-27 and is centered around three key reactions for the formation of uncialamycin: i) an addition of an acetylide (26) to a pyridinium species followed by ii) an intramolecular addition of $\mathbf{2 6}$ to form the enediyne core and iii) a Hauser annulation with fragment $\mathbf{2 7}$ to form the anthraquinone moiety (O Fig. 10) [73].

Fragment $\mathbf{2 5}$ was formed by starting with a two-step Friedländer quinoline synthesis [74]: condensation of 5-methoxyisatin (28) and methoxyenone (29) led to the ketocarboxylate 31 via intermediate 30; then $\mathbf{3 1}$ was reduced in situ to furnish the tricyclic lactone 32 with an $86 \%$ overall yield ( 0 Fig. 11). Thereafter, a deprotection/protection step of the phenol moiety yielded compound 33 with a $50 \%$ yield. After reduction of the lactone moiety

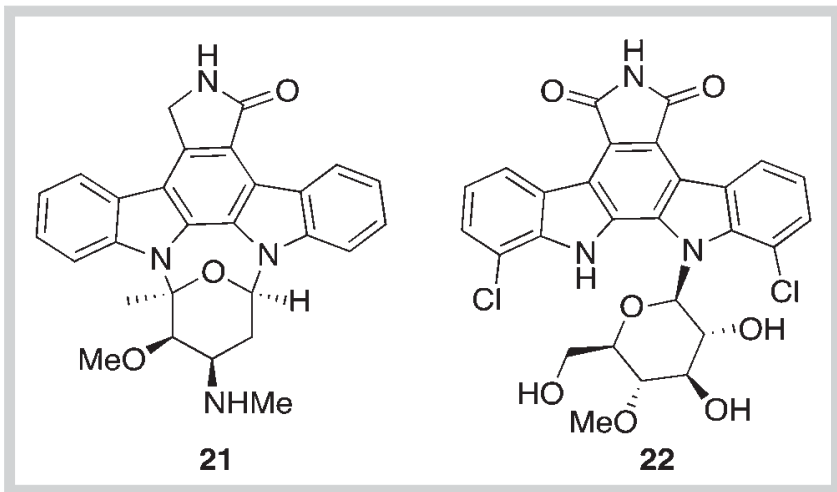

Fig. 8 Structures of staurosporine (21) and rebeccamycin (22).

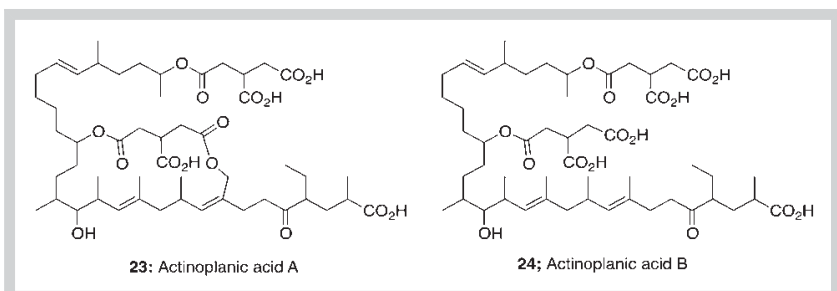

Fig. 9 Structures of actinoplanic acids A (23) and B (24).

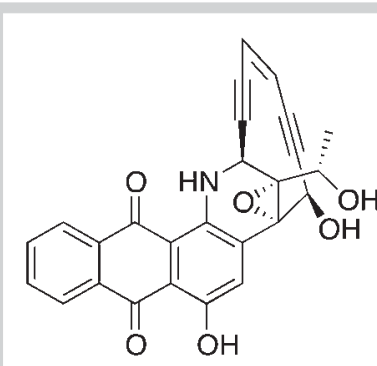

11a: (26S)-uncialamycin

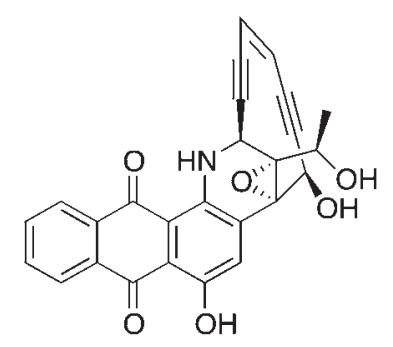

11b: (26R)-uncialamycin

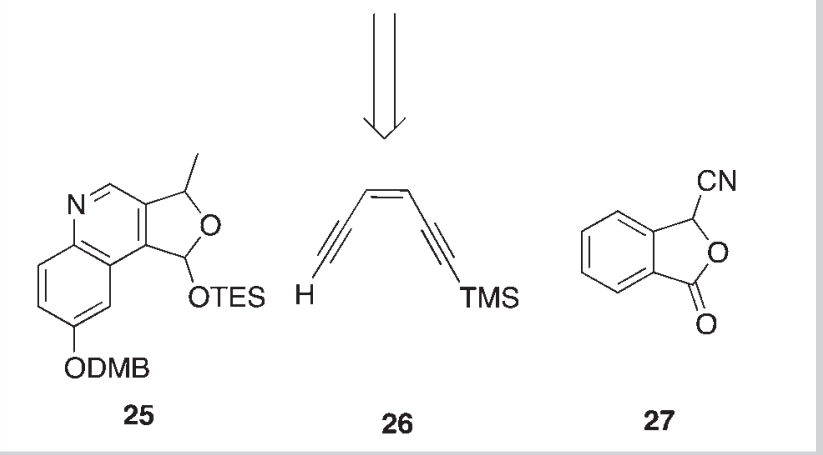

Fig. 10 Structures and retrosynthetic analysis of (26S)- and (26R)-uncialamycin (11a, 11b). DMB: 3,4-dimethoxybenzyl; TES: triethylsilyl; TMS: trimethylsilyl.

and protection of the obtained lactol, the quinoline system 25 was achieved with an $86 \%$ overall yield for the two steps and approximately a $1: 1$ mixture of diastereoisomers. 


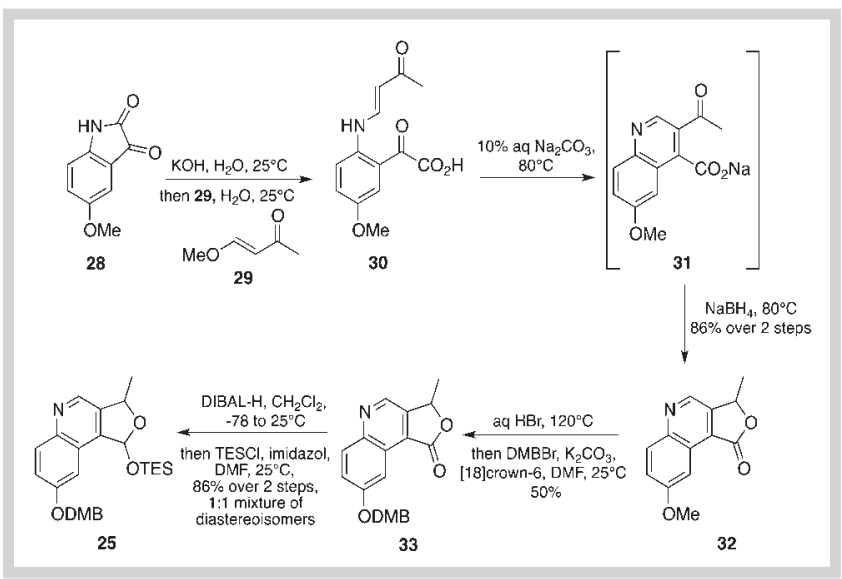

Fig. 11 Synthesis of quinoline $\mathbf{2 5}$.

The pyridine moiety of fragment $\mathbf{2 5}$ was activated by the formation of a pyridinium species, which was trapped by the acetylide derivative (26), generated from EtMgBr to afford the intermediate 34 with a $92 \%$ yield ( Fig. 12). After removal of the TES group, reduction of the lactol followed by a selective epoxidation and a monoacetylation yielded the hydroxyepoxide 35 (66\% overall yield for the three steps). After a protection/deprotection sequence leading to the formation of compound 36 (78\% overall yield for two steps), this latter one was submitted to an oxidation step of the hydroxyl group (87\% yield) and the deprotection of the phenol ( $87 \%$ yield) to obtain the aldehyde 37 . The cyclization, via an intramolecular acetylide addition, afforded the desired 10membered ring enediyne 38 (61\% yield, 70\% ee). Compound 38 was then oxidized to a semiquinone system ( $80 \%$ yield), and subsequent removal of the $\mathrm{N}$-protective group furnished the iminoquinone 39 ( $74 \%$ yield based on $70 \%$ conversion). At last, Hauser annulation of $\mathbf{3 9}$ with nitrile $\mathbf{2 7}$ in the presence of LiHMDS (63\% yield) and desilylation ( $3 \mathrm{HF} \times \mathrm{Et}_{3} \mathrm{~N}, 92 \%$ yield) gave ( $26 \mathrm{~S}$ )-uncialamycin (11a).

Comparison of NMR data of isolated uncialamycin and the (26S)isomer showed differences, which proved that the natural com- pound was not the $26 \mathrm{~S}$-isomer. To confirm these observations, Nicolaou and coworkers synthesized the 26R-epimer 11b. An oxidation/reduction sequence afforded the total inversion of the configuration at the C26 position (compound 41, 90\% overall yield, 96\% stereoselectivity; 0 Fig. 13). The 26R-epimer (41) was then submitted to the previously described routine ( $\bullet$ Fig. 12) to yield (26R)-uncialamycin (11b). The comparison of the spectroscopic data of this compound with the isolated one confirmed the configuration of the natural uncialamycin as the 26R-epimer. If this synthetic strategy provided an answer to the question of the relative configuration at $\mathrm{C} 26$, it did not solve the issue of the absolute configuration of the natural product. To obtain more stereochemistry information, Nicolaou et al. developed a catalytic asymmetric synthesis of uncialamycin (11; $\odot$ Fig. 14) [55]. The prochiral quinoline carboxylic acid $\mathbf{4 2}$ was converted to its methyl ester $\mathbf{4 3}$ with a $65 \%$ overall yield. Noyori reduction [75, 76] of the methyl ketone moiety within $\mathbf{4 3}$ resulted in the formation of $\gamma$-lactone 32, presumably via intermediate hydroxy ester 45, in a $95 \%$ yield and $93 \%$ ee. Conversion to compound 33 , necessary for the pursuit of the synthesis [73], under acidic conditions led to difficulties in maintaining the configurational integrity of the generated asymmetric center. To reach compound $\mathbf{3 3}$, another route has been envisaged starting from compound $\mathbf{4 2}$. Methyl ether carboxylic acid $\mathbf{4 2}$ was converted to DMB ether $\mathbf{4 6}$ ( $55 \%$ overall yield). Noyori reduction of $\mathbf{4 6}$ under the same conditions as those described previously for $\mathbf{4 3}$ furnished lactone $\mathbf{3 3}$ via intermediate $\mathbf{4 7}$, in a $95 \%$ yield and $98 \%$ ee. The intermediate 33 was then used to obtain (+)-uncialamycin (11, natural) and (+)-26-epi-uncialamycin as described for the synthesis of the racemic forms of these compounds [73].

One year after the realization of the first asymmetric synthesis of uncialamycin by Nicolaou's group, a second research group focused their interest on the synthesis of this metabolite. While Nicolaou and team introduced the asymmetry in their molecule almost at the end of their total synthesis, van de Weghe and coworkers based their approach on the preparation of a chiral quinoline by introducing the chirality from the second step of their synthetic strategy. They developed an intramolecular imino Diels-Alder reaction, based on the Povarov reaction, coupled to an oxidative aromatization that allowed the formation of substi-

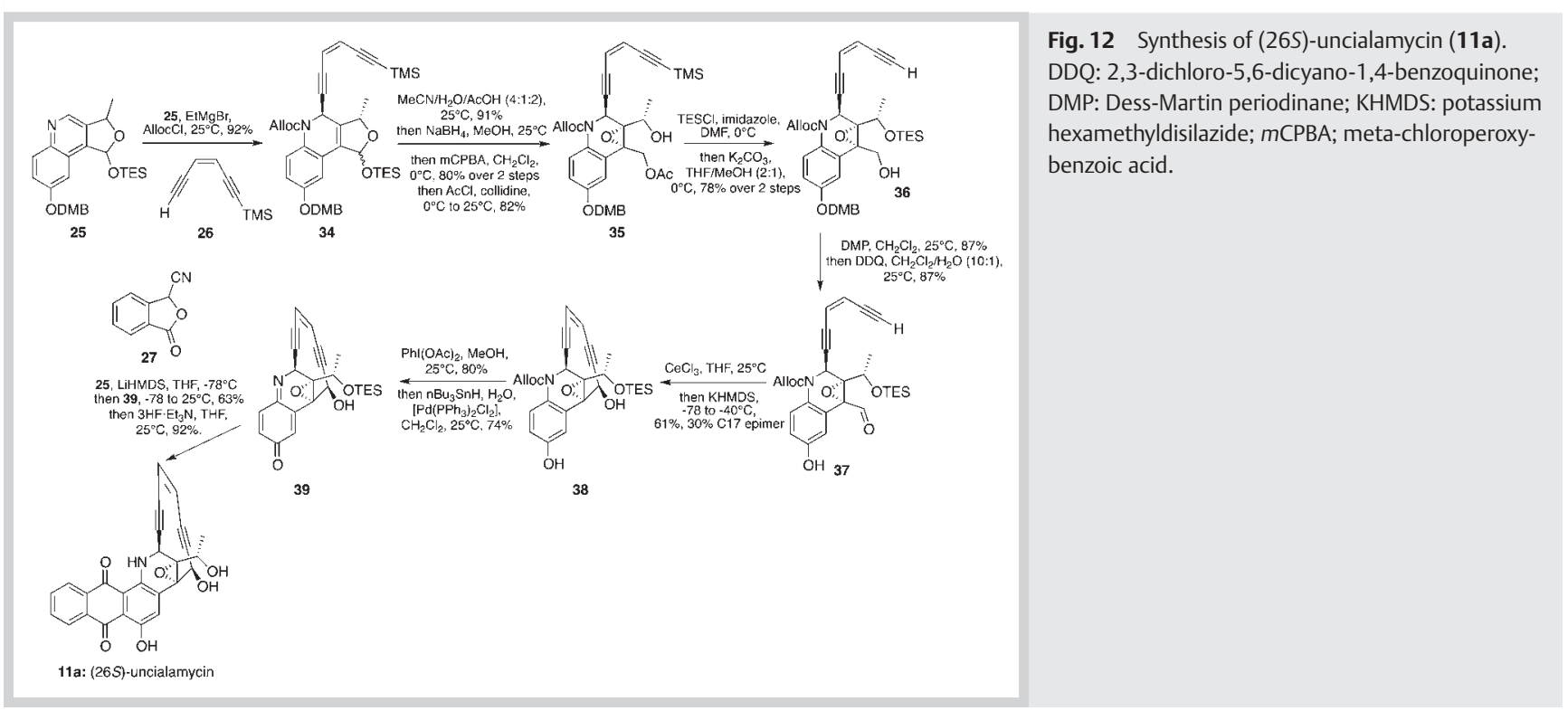




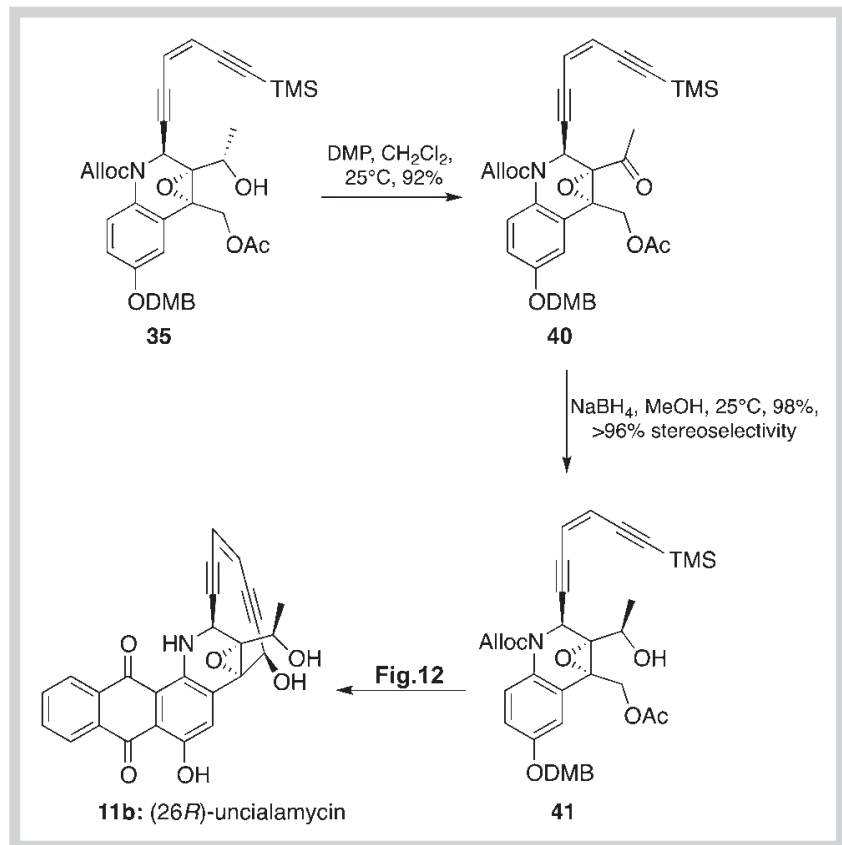

Fig. 13 Synthesis of (26R)-uncialamycin (11b).

tuted quinolones [77]. They used these reaction conditions to prepare the chiral quinoline moiety, as the chiral center C26 was fixed by an enantioselective reduction of an $\alpha$-alkyne ketone $\mathbf{4 8}$ affording the alcohol 49 with $80 \%$ ee. The enantiomeric excess has been determined by ${ }^{1} \mathrm{H}$ NMR after derivatization into its corresponding 0 -methylmandelic ester 56 . The alkynol 49 was converted in acryloyl ester $\mathbf{5 1}$ and the diol $\mathbf{5 2}$ was isolated as a diastereomeric mixture after an osmylation reaction with a $55 \%$ yield. The diol $\mathbf{5 2}$ was converted into its glyoxylic acid derivative and then transformed into the imine $\mathbf{5 3}$ ( Fig. 15). After imino-
Diels-Alder cycloaddition, the quinoline $\mathbf{5 4}$ was isolated in a $65 \%$ yield overall from the diol $\mathbf{5 2}$ with an $\mathbf{8 9 \%}$ ee as determined by HPLC.

Later, van de Weghe's group developed a second approach for the total synthesis of uncialamycin [78]. O Fig. 16 shows the retrosynthetic analysis of the construction of the quinoline core. Fragment 58 was obtained from a Michael-aldolization-crotonization reaction cascade starting from compounds 60 and $\mathbf{6 1}$. The acetylide addition to the activated quinoline moiety followed by a ring closure reaction led to the synthon 57.

The synthetic procedure started by the formation of the aniline derivative 63 using the Sugasawa reaction conditions [79]. This ortho-acylation has been achieved by condensation of chloroacetonitrile with compound $\mathbf{6 2}$, followed by a substantial $\mathrm{HCl}$ expulsion ( Fig. 17). The aniline derivative 63 was submitted to a Michael addition with methyl vinyl ketone 61 , which led to the Michael adduct 64. The aldolization of compound 64 has been successfully realized in the presence of $\mathrm{Cs}_{2} \mathrm{CO}_{3}$ under an oxygen atmosphere. The hemiketal 65 led to the ketone 66 in a $63 \%$ yield over two steps [80], which was reduced into the racemic alcohol 67. At last, a protection step of the secondary alcohol of $\mathbf{6 7}$ afforded compound 68 as the quinoline key fragment. The quinoline core was activated using methyl chloroformate [81] and trapped by the addition of the acetylide derived from enediyne 69 to furnish 70 in a good yield as a mixture of cis/trans isomers in an unchanged ratio of $6: 4$, which were separated by flash chromatography. Each isomer was then submitted to a deprotection step followed by an epoxidation. Compound 70-cis gave a unique isomer of the corresponding oxirane, while 70-trans led to a mixture. Further experiments were performed using the epoxide from 70-cis. After oxidation of the primary alcohol, the cyclization step was carried out and yielded a mixture of $\mathbf{7 2}$ and 73 in a ratio of $7: 3$. After isolation, NMR spectroscopic data of 72 showed a consistent similitude with the quinoline/enediyne moiety of the uncialamycin 11.

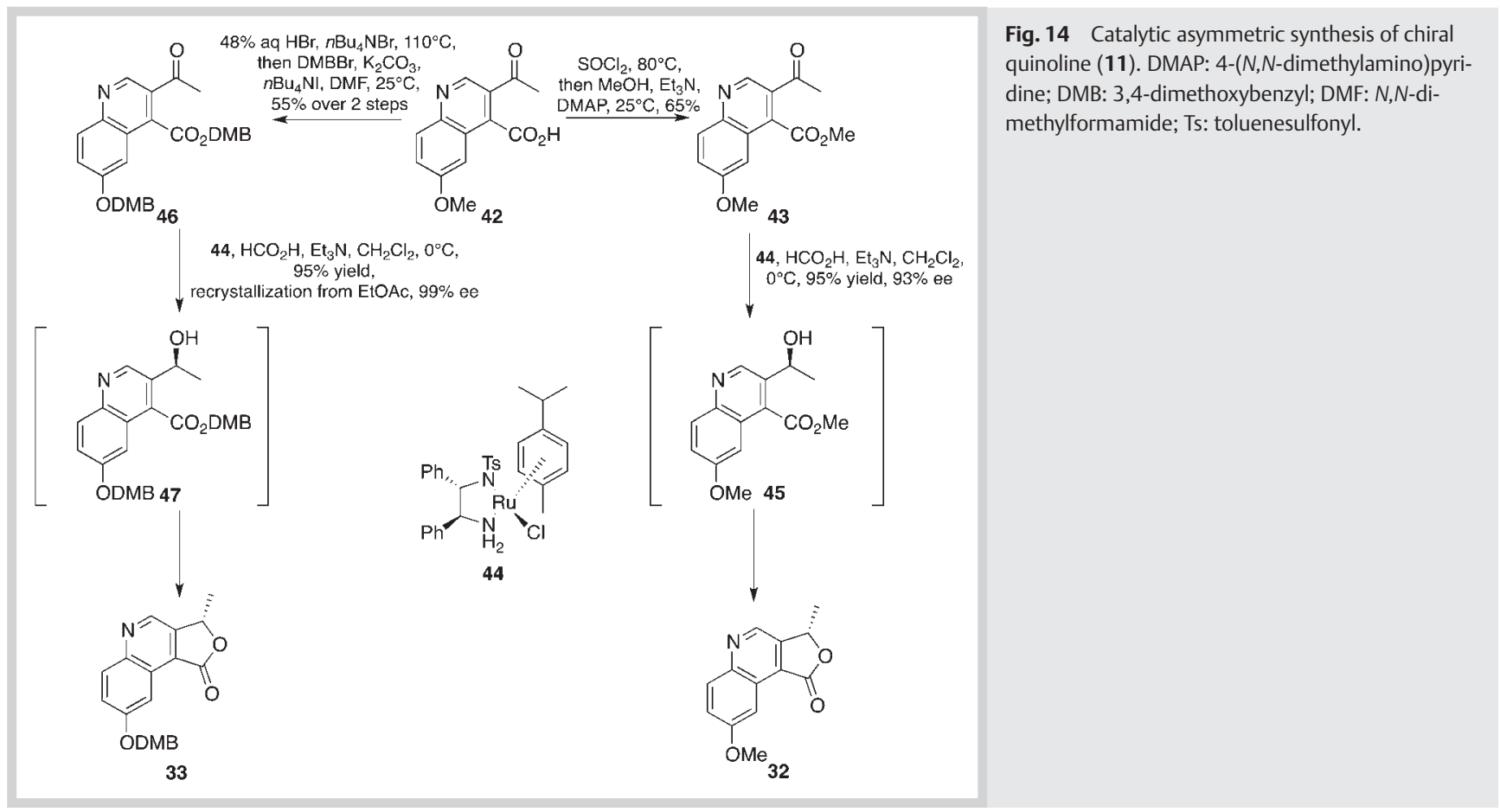




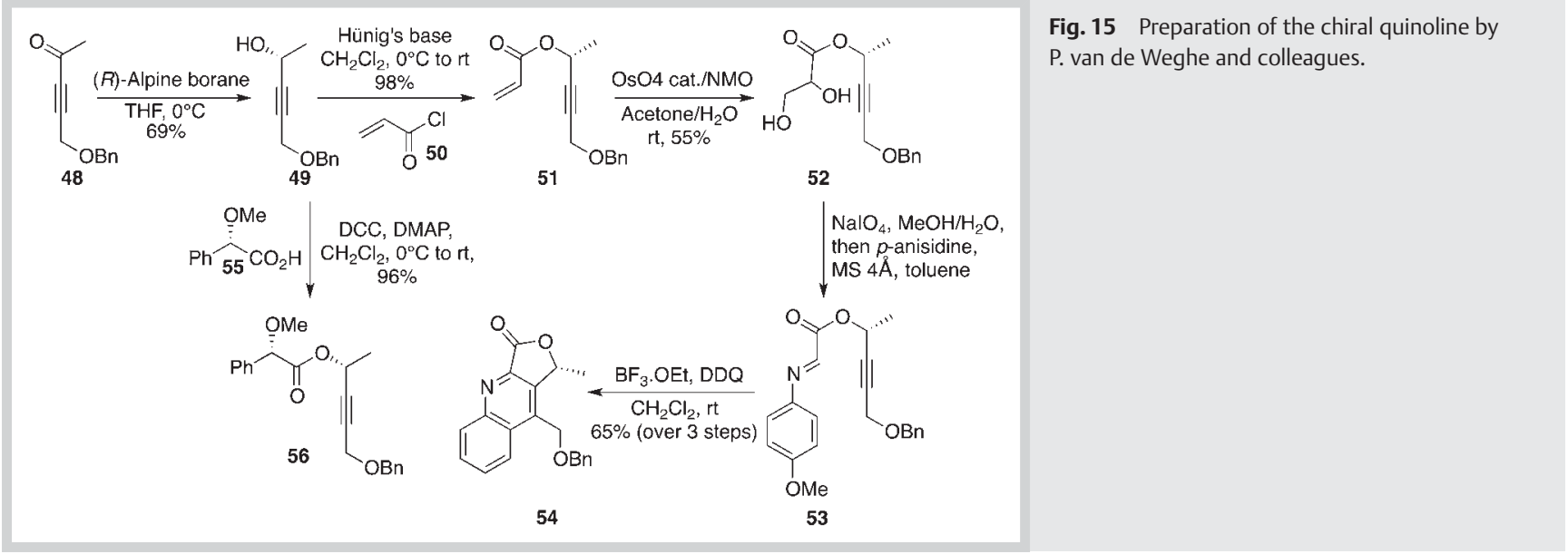

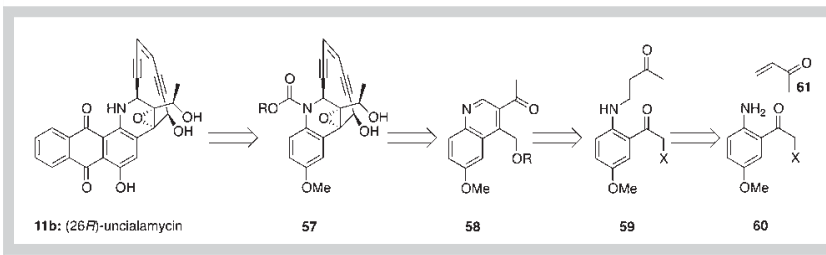

Fig. 16 Retrosynthetic approach developed by P. van de Weghe and colleagues.

\section{Conclusion}

$\nabla$

Lichens represent interesting microenvironments where a number of different organisms closely interact and have a rich bacterial diversity. Therefore, the lichen holobiont also has a very large potential for natural product discovery. So far, the bacterial diver- sity has been studied by various culture-dependent and cultureindependent molecular and microscopic approaches, which in almost all of the studies highlighted the prevalence of Alphaproteobacteria, Firmicutes, and Actinobacteria. Various abiotic and biotic factors affect this diversity, and as a consequence, structure and localization of the bacterial microbiome may be correlated with chemical patterns of metabolites released by all symbionts in the lichen thallus. Even if many roles of these bacteria still need to be experimentally confirmed, it seems now clearer that they contribute to various functions such as protection against biotic and abiotic stresses, nutrient cycling, reallocation of resources, detoxification, and other functions. The lichen-associated culturable bacteria have become a promising source of interesting bioactive metabolites, with most of them exhibiting potent activities. To date, uncialamycin constitutes one of the most exciting compounds as it presents a broad variety of biological activities associated with a unique and specific mechanism of action. Two main approaches in the design of this compound have been

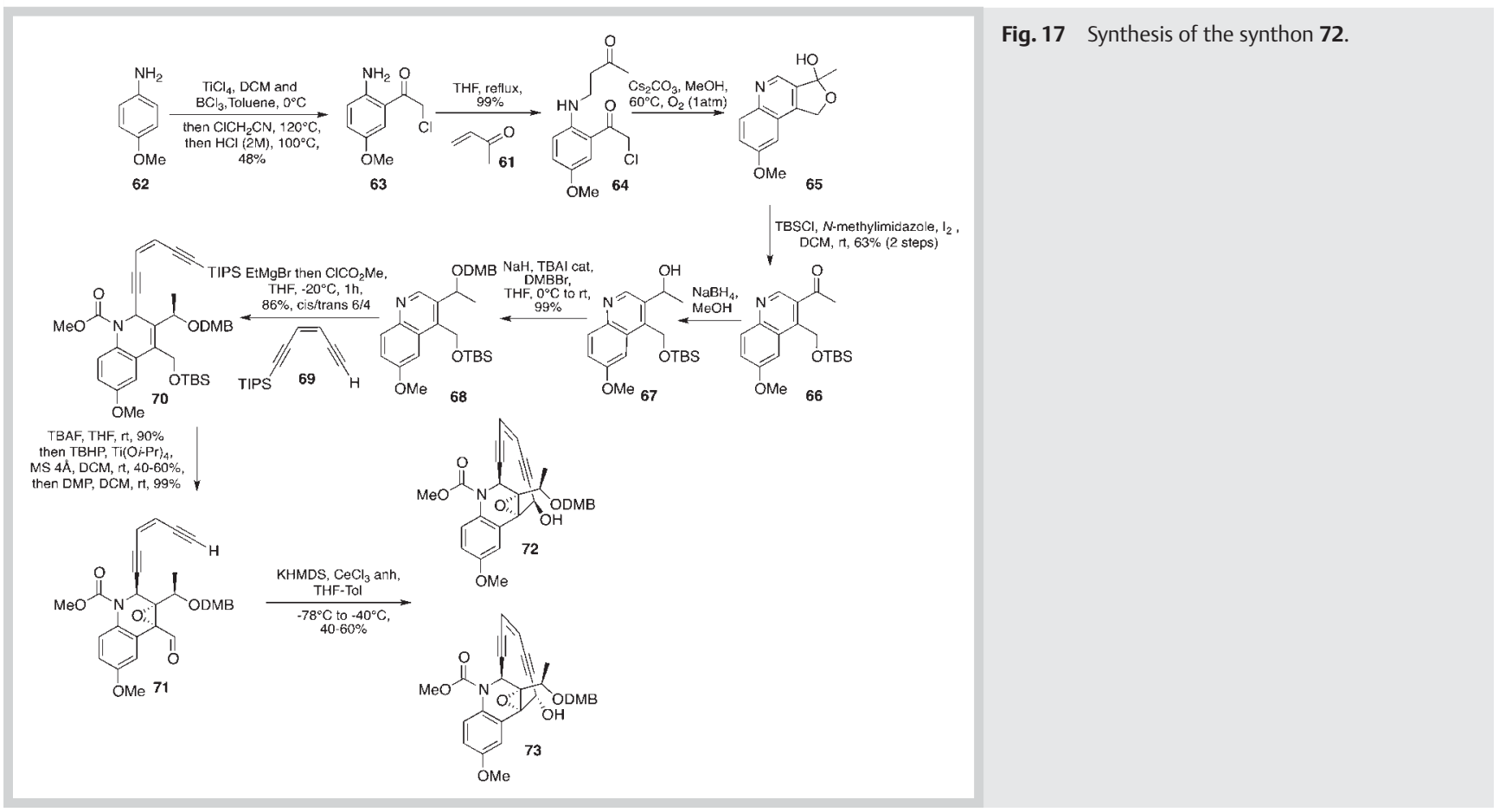


undertaken and highlight the structurally complex enediyne derivatives as a challenging target for chemists. One of the strategies allowed for the determination of the configuration of the natural compound. These major breakthroughs paved the way for the synthesis of analogues and new related enediynes, which could become new pharmaceutical leads. Finally, these data confirm the real biotechnological interest of lichen-associated bacteria as an untapped source of interesting metabolites with useful activity. The next challenges will be to explore the whole metabolome of these bacteria by activating silent biosynthetic pathways. One of the approaches could be based on coculture studies.

\section{Acknowledgements}

This work was partly supported by EMR, a partnership between the UPMC, Laboratoires Pierre Fabre and the CNRS, by the project ANR MALICA (10-INBS-02-01), UFR Sciences Pharmaceutiques et Biologiques of Rennes for a grant for N. Legrave, as well as INSA, Rennes for the PhD grant of D. Parrot, Rennes Metropole, and PhD Amadeus for the exchange with Austria. We thank Nyree West, Laurent Intertaglia for fruitful discussions.

\section{Conflict of Interest}

\section{$\nabla$}

The authors declare that they have no conflict of interest.

\section{References}

1 Ling LL, Schneider T, Peoples AJ, Spoering AL, Engels I, Conlon BP, Mueller $A$, Hughes DE, Epstein S, Jones M, Lazarides L, Steadman VA, Cohen DR, Felix CR, Fetterman KA, Millett WP, Nitti AG, Zullo AM, Chen C, Lewis K. A new antibiotic kills pathogens without detectable resistance. Nature 2015; 517: 455-459

2 Lauterwein $M$, Oethinger $M$, Belsner $K$, Peters T, Marre R. In vitro activities of the lichen secondary metabolites vulpinic acid, (+)-usnic acid, and (-)-usnic acid against aerobic and anaerobic microorganisms. Antimicrob Agents Chemother 1995; 39: 2541-2543

3 Ingólfsdóttir K. Usnic acid. Phytochemistry 2002; 61: 729-736

4 Molnár K, Farkas E. Current results on biological activities of lichen secondary metabolites: a review. Z Naturforsch C 2010; 65: 157-173

5 Shrestha G, St. Clair LL. Lichens: a promising source of antibiotic and anticancer drugs. Phytochem Rev 2013; 12: 229-244

6 Shukla V, Joshi GP, Rawat MSM. Lichens as a potential natural source of bioactive compounds: a review. Phytochem Rev 2010; 9: 303-314

7 Boustie J, Grube M. Lichens - a promising source of bioactive secondary metabolites. Plant Genet. Ressources 2005; 3: 273-287

8 Boustie J, Tomasi S, Grube M. Bioactive lichen metabolites: alpine habitats as an untapped source. Phytochem Rev 2011; 10: 287-307

9 Hawksworth DL. The lichenicolous fungi of Great Britain and Ireland: an overview and annotated checklist. Lichenologist 2003; 35: 191-232

10 Lawrey J, Diederich P. Lichenicolous fungi: interactions, evolution, and biodiversity. Bryologist 2003; 106: 80-120

11 González I, Ayuso-Sacido A, Anderson A, Genilloud O. Actinomycetes isolated from lichens: evaluation of their diversity and detection of biosynthetic gene sequences. FEMS Microbiol Ecol 2005; 54: 401-415

12 Cardinale M, Puglia AM, Grube M. Molecular analysis of lichen-associated bacterial communities. FEMS Microbiol Ecol 2006; 57: 484-495

13 Cardinale M, Vieira de Castro jr. J, Müller H, Berg G, Grube M. In situ analysis of the bacterial community associated with the reindeer lichen Cladonia arbuscula reveals predominance of Alphaproteobacteria. FEMS Microbiol Ecol 2008; 66: 63-71

14 Cardinale M, Grube M, Castro jr. JV, Müller H, Berg G. Bacterial taxa associated with the lung lichen Lobaria pulmonaria are differentially shaped by geography and habitat. FEMS Microbiol Lett 2012; 329: 111-115

15 Liba CM, Ferrara FIS, Manfio GP, Fantinatti-Garboggini F, Albuquerque RC, Pavan C, Ramos PL, Moreira-Filho C, Barbosa HR. Nitrogen-fixing chemo-organotrophic bacteria isolated from cyanobacteria-deprived lichens and their ability to solubilize phosphate and to release amino acids and phytohormones. J Appl Microbiol 2006; 101: 1076-1086

16 Grube M, Berg G. Microbial consortia of bacteria and fungi with focus on the lichen symbiosis. Fungal Biol Rev 2009; 23: 72-85

17 Grube M, Cardinale M, de Castro jr. JV, Müller H, Berg G. Species-specific structural and functional diversity of bacterial communities in lichen symbioses. ISME J 2009; 3: 1105-1115

18 Hodkinson BP, Lutzoni F. A microbiotic survey of lichen-associated bacteria reveals a new lineage from the Rhizobiales. Symbiosis 2009; 49: 163-180

19 Schneider T, Schmid E, de Castro jr. JV, Cardinale M, Eberl L, Grube M, Berg G, Riedel K. Structure and function of the symbiosis partners of the lung lichen (Lobaria pulmonaria L. Hoffm.) analyzed by metaproteomics. Proteomics 2011; 11: 2752-2756

20 Bates ST, Cropsey GWG, Caporaso JG, Knight R, Fierer N. Bacterial communities associated with the lichen symbiosis. Appl Environ Microbiol 2011; 77: 1309-1314

21 Muggia L, Vancurova L, Škaloud P, Peksa O, Wedin M, Grube M. The symbiotic playground of lichen thalli - a highly flexible photobiont association in rock-inhabiting lichens. FEMS Microbiol Ecol 2013; 85: 313323

22 Grube M, Cernava T, Soh J, Fuchs S, Aschenbrenner I, Lassek C, Wegner U, Becher D, Riedel K, Sensen CW, Berg G. Exploring functional contexts of symbiotic sustain within lichen-associated bacteria by comparative omics. ISME J 2015; 9: 1-13

23 Cardinale M, Steinová J, Rabensteiner J, Berg G, Grube M. Age, sun and substrate: triggers of bacterial communities in lichens. Environ Microbiol Rep 2012; 4: 23-28

24 Grube M, Berg G, Andrésson ÓS, Vilhelmsson O, Dyer PS, Miao VPW. Lichen genomics: prospects and progress. In: Martin F, Editor. The ecological genomics of fungi. New York: John Wiley \& Sons; 2014: 191-212

25 Printzen C, Fernández-Mendoza F, Muggia L, Berg G, Grube M. Alphaproteobacterial communities in geographically distant populations of the lichen Cetraria aculeata. FEMS Microbiol Ecol 2012; 82: 316-325

26 Bjelland T, Grube M, Hoem S, Jorgensen SL, Daae FL, Thorseth IH, Øvreås L. Microbial metacommunities in the lichen-rock habitat. Environ Microbiol Rep 2011; 3: 434-442

27 An SY, Xiao T, Yokota A. Leifsonia lichenia sp. nov., isolated from lichen in Japan. J Gen Appl Microbiol 2009; 55: 339-343

28 An SY, Xiao T, Yokota A. Schumannella luteola gen. nov., sp. nov., a novel genus of the family Microbacteriaceae. J Gen Appl Microbiol 2008; 258: 253-258

29 Cheenpracha S, Vidor NB, Yoshida WY, Davies J, Chang LC. Coumabiocins A-F, aminocoumarins from an organic extract of Streptomyces sp. L-44. J Nat Prod 2010; 73: 880-884

30 Davies J, Wang H, Taylor T, Warabi K, Huang XH, Andersen RJ. Uncialamycin, a new enediyne antibiotic. Org Lett 2005; 7: 5233-5236

$31 \mathrm{Li}$ B, Xie CH, Yokota A. Nocardioides exalbidus sp. nov., a novel actinomycete isolated from lichen in Izu-Oshima Island, Japan. Actinomycetologica 2007; 21: 22-26

32 Motohashi K, Takagi M, Yamamura H, Hayakawa M, Shin-ya K. A new angucycline and a new butenolide isolated from lichen-derived Streptomyces spp. J Antibiot (Tokyo) 2010; 63: 545-548

33 Selbmann L, Zucconi L, Ruisi S, Grube M, Cardinale M, Onofri S. Culturable bacteria associated with Antarctic lichens: affiliation and psychrotolerance. Polar Biol 2009; 33: 71-83

34 Williams DE, Davies J, Patrick BO, Bottriell H, Tarling T, Roberge M, Andersen RJ. Cladoniamides A-G, tryptophan-derived alkaloids produced in culture by Streptomyces uncialis. Org Lett 2008; 10: 3501-3504

35 Parrot D, Antony-Babu S, Intertaglia L, Grube M, Tomasi S, Suzuki MT. Littoral lichens as a novel source of potentially bioactive Actinobacteria. Sci Rep 2015; 5: 15839

36 Yamamura H, Ashizawa H, Nakagawa Y, Hamada M, Ishida Y, Otoguro M, Tamura T, Hayakawa M. Actinomycetospora iriomotensis sp. nov., a novel actinomycete isolated from a lichen sample. J Antibiot 2011; 64: 289-292

37 Suzuki MT, Parrot D, Berg G, Grube M, Tomasi S. Lichens as natural sources of biotechnologically relevant bacteria. Appl Microbiol Biotechnol 2016; 100: 583-595

38 Grube M, Köberl M, Lackner S, Berg C, Berg G. Host-parasite interaction and microbiome response: effects of fungal infections on the bacterial community of the Alpine lichen Solorina crocea. FEMS Microbiol Ecol 2012; 82: 472-481 
39 Hodkinson BP, Gottel NR, Schadt CW, Lutzoni F. Photoautotrophic symbiont and geography are major factors affecting highly structured and diverse bacterial communities in the lichen microbiome. Environ Microbiol 2012; 14: 147-161

40 Mushegian AA, Peterson CN, Baker CMC, Pringle A. Bacterial diversity across individual lichens. Appl Environ Microbiol 2011; 77: 4249-4252

41 Sigurbjörnsdóttir MA, Heiðmarsson S, Jónsdóttir AR, Vilhelmsson 0. Novel bacteria associated with Arctic seashore lichens have potential roles in nutrient scavenging. Can J Microbiol 2014; 92: 307-317

42 Navarro-Noya YE, Jiménez-Aguilar A, Valenzuela-Encinas C, AlcántaraHernández J, Ruíz-Valdiviezo VM, Ponce-Mendoza A, Luna-Guido $M$, Marsch R, Dendooven L. Bacterial communities in soil under moss and lichen-moss crusts. Geomicrobiol J 2014; 31: 152-160

43 Davies J, Ryan KS. Introducing the parvome: bioactive compounds in the microbial world. ACS Chem Biol 2012; 7: 252-259

44 Williams DE, Bottriell H, Davies J, Tietjen I, Brockman MA, Andersen RJ. Unciaphenol, an Oxygenated Analogue of the Bergman Cyclization Product of Uncialamycin Exhibits Anti-HIV Activity. Org Lett 2015; 17 : 5304-5307

45 Cardinale M, Grube M, Berg G. Frondihabitans cladoniiphilus sp. nov., an actinobacterium of the family Microbacteriaceae isolated from lichen, and emended description of the genus Frondihabitans. Int J Syst Evol Microbiol 2011; 61: 3033-3038

46 Singh S, Garrity G, Genillourd O, Lingham R, Martin I, Nallin-Omstead M, Silverman $K$, Zink $D$. Inhibitor compounds of farnesyl-protein transferase and chemotherapeutic compositions containing the same, produced by strain ATCC 55532. US Patent 5627057; 1997

47 Braña AF, Fiedler HP, Nava H, González V, Sarmiento-Vizcaíno A, Molina A, Acuña JL, García LA, Blanco G. Two Streptomyces species producing antibiotic, antitumor, and anti-inflammatory compounds are widespread among intertidal macroalgae and deep-sea coral reef invertebrates from the central Cantabrian Sea. Microb Ecol 2015; 69: 512-524

48 Takahashi $Y$, Omura S. Isolation of new actinomycete strains for the screening of new bioactive compounds. J Gen Appl Microbiol 2003; 49: $141-154$

49 Murphy B, Jensen P, Fenical W. The chemistry of marine bacteria. In: Fattorusso E, Gerwick W, Taglialatela-Scafati O, editors. Handbook of marine natural products. Dordrecht: Springer Netherlands; 2012: 153-190

50 Waters B, Saxena G, Wanggui Y, Kau D, Wrigley S, Stokesd R, Davies J. Identifying protein kinase inhibitors using an assay based on inhibition of aerial hyphae formation in Streptomyces. J Antibiot 2002; 55: 407416

51 Yao G, Vidor NB, Foss AP, Chang LC. Lemnalosides A-D, decalin-type bicyclic diterpene glycosides from the marine soft coral Lemnalia $\mathrm{sp}$. J Nat Prod 2007; 70: 901-905

52 Raad I, Hachem R, Abi-Said D, Rolston K, Whimbey E, Buzaid A, Legha S. A prospective crossover randomized trial of novobiocin and rifampin prophylaxis for the prevention of intravascular catheter infections in cancer patients treated with interleukin-2. Cancer 1998; 82: 403-411

53 Walsh TJ, Standiford HC, Reboli AC, John JF, Mulligan ME, Ribner BS, Montgomerie JZ, Goetz MB, Mayhall CG, Rimland D. Randomized double-blinded trial of rifampin with either novobiocin or trimethoprimsulfamethoxazole against methicillin-resistant Staphylococcus aureus colonization: prevention of antimicrobial resistance and effect of host factors on outcome. Antimicrob Agents Chemother 1993; 37: 13341342

54 Konishi M, Ohkuma H, Tsuno T, Oki T. Crystal and molecular structure of dynemicin 1: a novel 1, 5-diyn-3-ene antitumor antibiotic. J Am Chem Soc 1990; 112: 3715-3716

55 Nicolaou KC, Chen JS, Zhang H, Montero A. Asymmetric synthesis and biological properties of uncialamycin and 26-epi-uncialamycin. Angew Chem Int Ed Engl 2008; 47: 185-189

56 Jean $M$, Tomasi $S$, van de Weghe $P$. When the nine-membered enediynes play hide and seek. Org Biomol Chem 2012; 10: 7453-7456

57 Damle NK. Tumour-targeted chemotherapy with immunoconjugates of calicheamicin. Expert Opin Biol Ther 2004; 4: 1445-1452

58 Berger M, Leopold L, Dowell J, Korth-Bradley J, Sherman M. Licensure of gemtuzumab ozogamicin for the treatment of selected patients 60 years of age or older with acute myeloid leukemia in first relapse. Invest New Drugs 2002; 20: 395-406

59 Hamann PR, Hinman LM, Beyer CF, Greenberger LM, Lin C, Lindh D, Menendez AT, Wallace R, Durr FE, Upeslacis J. An anti-MUC1 antibodycalicheamicin conjugate for treatment of solid tumors. Choice of linker and overcoming drug resistance. Bioconjug Chem 2005; 16: 346-353

60 Bergman RG. Reactive 1, 4-dehydroaromatics. Acc Chem Res 1973; 6: 25-31

61 Myers AG, Fraley ME, Tom NJ, Cohen SB, Madar DJ. Synthesis of (+)-dynemicin A and analogs of wide structural variability: establishment of the absolute configuration of natural dynemicin A. Chem Biol 1995; 2: $33-$ 43

62 Smith AL, Nicolaou KC. The enediyne antibiotics. J Med Chem 1996; 39: 2103-2117

63 Sanchez C, Mendez C, Salas JA. Indolocarbazole natural products: occurrence, biosynthesis, and biological activity. Nat Prod Rep 2006; 23 : 1007-1045

64 Howard-Jones AR, Walsh CT. Staurosporine and rebeccamycin aglycones are assembled by the oxidative action of StaP, StaC, and RebC on chromopyrrolic acid. J Am Chem Soc 2006; 128: 12289-12298

65 Hyun CG, Bililign T, Liao J, Thorson JS. The biosynthesis of indolocarbazoles in a heterologous E. coli host. Chembiochem 2003; 4: 114-117

66 Howard-Jones AR, Walsh CT. Enzymatic generation of the chromopyrrolic acid scaffold of rebeccamycin by the tandem action of RebO and RebD. Biochemistry 2005; 44: 15652-15663

67 Sánchez C, Méndez C, Salas J. Engineering biosynthetic pathways to generate antitumor indolocarbazole derivatives. J Ind Microbiol Biotechnol 2006; 33: 560-568

68 Sánchez C, Zhu L, Braña AF, Salas AP, Rohr J, Méndez C, Salas JA. Combinatorial biosynthesis of antitumor indolocarbazole compounds. Proc Natl Acad Sci U S A 2005; 102: 461-466

69 Zhang C, Albermann C, Fu X, Peters NR, Chisholm JD, Zhang G, Gilbert EJ, Wang PG, Van Vranken DL, Thorson JS. RebG- and RebM-catalyzed indolocarbazole diversification. Chembiochem 2006; 7: 795-804

70 Singh SB, Liesch JM, Lingham RB, Goetz MA, Gibbst JB. Actinoplanic acid A: a macrocyclic polycarboxylic acid which is a potent inhibitor of Ras farnesyl-protein transferase. J Am Chem Soc 1994; 116: 11606-11607

71 Silverman K, Cascales C, Genilloud O, Sigmund J, Gartner S, Koch G, Gagliardi M, Heimbuch BK, Nallin-Omstead M, Sanchez M, Diez M, Martin I, Garrity G, Hirsch C, Gibbs J, Singh S, Lingham R. Actinoplanic acids A and $B$ as novel inhibitors of farnesyl-protein transferase. Appl Microbiol Biotechnol 1995; 43: 610-616

72 Fernandez-Medarde A, Santos E. Ras in cancer and developmental diseases. Genes Cancer 2011; 2: 344-358

73 Nicolaou KC, Zhang H, Chen JS, Crawford JJ, Pasunoori L. Total synthesis and stereochemistry of uncialamycin. Angew Chem Int Ed Engl 2007; 46: 4704-4707

74 Bretschneider $H$, Hohenlohe-Oehringen $K$, Rhomberg A. 3-acetyl-cinchoninic acid compounds. US Patent 3311632; 1967

75 Fujii A, Hashiguchi S, Uematsu N, Ikariya T, Noyori R. Ruthenium(II)-catalyzed asymmetric transfer hydrogenation of ketones using a formic acid-triethylamine mixture. J Am Chem Soc 1996; 118: 2521-2522

76 Noyori R, Hashiguchi S. Asymmetric transfer hydrogenation catalyzed by chiral ruthenium complexes. Acc Chem Res 1997; 30: 97-102

77 Desrat S, van de Weghe P. Intramolecular imino Diels-Alder reaction: progress toward the synthesis of uncialamycin. J Org Chem 2009; 74 : 6728-6734

78 Desrat S, Jean $M$, van de Weghe P. Setbacks and hopes: en route to the synthesis of uncialamycin. Tetrahedron 2011; 67: 7510-7516

79 Prasad K, Lee GT, Chaudhary A, Girgis MJ, Streemke JW, Repič O. Design of new reaction conditions for the Sugasawa reaction based on mechanistic insights. Org Process Res Dev 2003; 7: 723-732

80 Bartoszewicz A, Kalek M, Stawinski J. Iodine-promoted silylation of alcohols with silyl chlorides. Synthetic and mechanistic studies. Tetrahedron 2008; 64: 8843-8850

81 Myers AG, Tom NJ, Fraley ME, Cohen SB, Madar DJ. A convergent synthetic route to (+)-dynemicin A and analogs of wide structural variability. J Am Chem Soc 1997; 7863: 6072-6094 